\title{
Knowledge Regarding the Benefits of Physiotherapy among Physiotherapy Specialty Students
}

\author{
Maral F. Thabit ${ }^{1}$, Mostafa J. Jasim² \\ ${ }^{1}$ Ass. Professor, Middle Technical University, Medical Technical Institute, Baghdad, \\ ${ }^{2}$ Lecturer, Middle Technical University, Medical Technical Institute, Baghdad
}

\begin{abstract}
Background: Physical treatment is a unique calling with broad clinical applications in the rebuilding, support and advancement of ideal physical capacity
\end{abstract}

Aim of study: To assess the level of knowledge regarding the benefits of physiotherapy among Physiotherapy Specialty students.

Methodology: A cross sectional descriptive study included (54) Physiotherapy students of Medical Technical Institute, Technical College of Health and Medicine/Baghdad, during November and December 2018.

They were selected randomly and they were asked to answer a self-administered questionnaire in 3 main domains (general benefits, woman's health, chronic disease management) of physiotherapy. The questionnaire covered different aspects regarding the knowledge of the benefits of physiotherapy. The percent score for each question and overall mean score for each domain was assessed.

Results: The total number of included students in the study was 54 distributed an $51.9 \%$ males $48.1 \%$ females, $64.81 \%$ from the Medical Technical Institute and 35.19\%from the college of Technical Health and Medicine. Distribution of knowledge of students regarding the general benefits of physiotherapy was with overall mean percent score $=80$, women's health with overall mean percent score $=67 \%$ and for the benefits of physiotherapy in chronic diseases with overall mean percent score $=84 \%$. The overall mean percent scores for all domains were 77 .

Conclusion: In general, satisfactory level of knowledge of included students regarding the benefits of physiotherapy.

Keywords: Physiotherapy, Benefits, Knowledge, Students.

\section{Introduction}

Physiotherapy (PT) is treatment to reestablish, keep up and take advantage of the patient's portability, capacity and prosperity. It will help physical restoration, injury counteraction and wellbeing and wellness. Nonintrusive treatment is utilized to improve a patient's personal satisfaction through assessment, conclusion, visualization, physical intercession, and patient training. ${ }^{(1)}$

Physiotherapists (PTs) are medical services experts who analyze and treat people, everything being equal, who have clinical and other related issues that limit their capacities to move and perform utilitarian exercises in their day by day lives. ${ }^{(2,3)}$

PT the board incorporates explicit activities, manual treatment and control, mechanical gadgets, for example, foothold, instruction, electro physical modalities which incorporate warmth, cold, power, sound waves, radiation, assistive gadgets, prostheses, orthoses and different mediations. ${ }^{(4)}$

Active recuperation administrations might be given as essential consideration therapy or close by, or related to, other clinical administrations (including clinics, private practices or outpatient centers. ${ }^{(1)}$ 
Physiotherapy can be given distinctly by qualified physical advisors or physical specialist partners ${ }^{(2)}$. Physiotherapy therapy alternatives for: Problems brought about by wounds, infections and handicaps, neck and back torment, solid and tendon conditions, for example, joint pain and after removals, lung and heart issues, bladder and entrail issues brought about by labor likewise malignancy treatment (palliative consideration). loss of portability sicknesses because of injury to cerebrum or spine or infections like different sclerosis and Parkinson's malady. ${ }^{(5)}$

A few dated worldwide examinations have analyzed the information view of physiotherapy by physiotherapy understudies $^{(6)}$ Health Science understudies. ${ }^{(7)}$

To the best of our knowledge.no study has been acted in Iraq that has assessed the information on physiotherapy college understudies about the advantages of physiotherapy as a calling. The consequences of this examination could help in recommending medical care ways for the improvement of physiotherapy calling for ideal patient consideration.

Aim of study: To assess the level of knowledge regarding the benefits of physiotherapy among Physiotherapy specialty students.

\section{Subjects and Method}

After all ethical permissions were obtained from the institutional and college Scientific Counsel. A cross sectional descriptive study included (54) second year undergraduate Physiotherapy students of Medical Technical Institute/Baghdad and Technical College of Health and Medicine/Baghdad was conducted. Data was collected during November and December 2018.

They were selected randomly and an invitation to participate in the study along with the explanation of its importance was achieved and willing students gave verbal consents and the data was collected through answering a self-administered. questionnaire. The questionnaire included various sections about students' demographics, knowledge of the benefits of physiotherapy in three domains (general benefits, benefits regarding women health, management of chronic diseases by physiotherapy techniques). Descriptive statistics including frequencies and percentages were used for demographic data analysis. Each knowledge question responses were scored as (3) for each yes answer, (2) for answering don't know and (1) for answering (No).

The percent score for students' responses in each specific question was calculated according to the following equation:

All out scores for all understudies in each question X 100/most extreme potential scores for all included understudies for a similar inquiry. Where complete scores for all members in the question $=[($ No. of no $x 1)+$ (No. of don't know x 2) + (No. of yes x 3)]. Furthermore, most extreme potential scores for all members in the equivalent question $=[$ No. of complete understudies' $\mathrm{x}$ 3], in light of Triple Likert Scale ${ }^{(8)}$.

\section{Results}

The total number of included students in the study was 54 distributed an $51.9 \%$ males $48.1 \%$ females, $64.81 \%$ from the Medical Technical Institute/Baghdad and $35.19 \%$ from the college of Technical Health and Medicine, $29.62 \%$ of students were $<20$ years and $70.38 \% \geq 20$ years, as shown in table 1 :

\section{Table 1: Distribution of students regarding socio demographic characteristics: $(\mathrm{N}=54)$}

\begin{tabular}{|l|c|c|}
\hline Socio Demographic Characteristics & No & $\%$ \\
\hline Gender & 28 & 51.9 \\
\hline Male & 26 & 48.1 \\
\hline Female & 35 & 64.81 \\
\hline Academic Setting & 19 & 35.19 \\
\hline Institute & & \\
\hline College & 16 & 29.62 \\
\hline Age & 38 & 70.38 \\
\hline$<20$ years &
\end{tabular}

The distribution of students' responses regarding the general benefitsof physiotherapy was highly correct $94.44 \%, 79.6 \%, 77.77 \%$ with percent score $98 \%, 90 \%$, $86 \%$ regarding recovery from sport injuries, improving balance by using assisting devices, reduction of muscle and joint pain by using therapeutic exercises. While the lowest proportion of correct responses $16.66 \%, 18.51 \%$ with percent score $60 \%, 57 \%$ regarding the help in the recovery of patient with cerebral palsy and recovery from vertigo condition respectively. The overall percent score for this domain is $79.66 \%$ as shown in table (2). 
Table 2: Distribution of knowledge of students regarding the general benefits of physiotherapy. $(\mathrm{N}=54)$

\begin{tabular}{|c|c|c|c|c|c|c|c|}
\hline \multirow{2}{*}{ Benefits of physiotherapy } & \multicolumn{2}{|c|}{ Yes } & \multicolumn{2}{|c|}{ No } & \multicolumn{2}{|c|}{ Don't Know } & \multirow{2}{*}{$\begin{array}{l}\text { Percent } \\
\text { score }\end{array}$} \\
\hline & No & $\%$ & No & $\%$ & No & $\%$ & \\
\hline $\begin{array}{l}\text { 1. To reduce muscle and joint pain by using therapeutics } \\
\text { exercises . }\end{array}$ & 42 & 77.77 & 11 & 20.37 & 1 & 1.85 & 86 \\
\hline 2. To avoid surgery sometimes & 42 & 77.77 & 12 & 22.22 & 0 & 0 & 85 \\
\hline $\begin{array}{l}\text { 3. To recover before surgery and to decrease health care } \\
\text { costs . }\end{array}$ & 32 & 59.25 & 17 & 31.48 & 5 & 9.25 & 76 \\
\hline $\begin{array}{l}\text { 4. To improve mobility by doing stretching and strong } \\
\text { theming exercises. }\end{array}$ & 39 & 72.22 & 7 & 12.96 & 8 & 14.81 & 86 \\
\hline 5. To improve balance by using assisting devices & 43 & 79.62 & 5 & 9.25 & 6 & 11.11 & 90 \\
\hline 6. To help in using orthosis & 32 & 59.25 & 3 & 5.55 & 19 & 35.18 & 84 \\
\hline 7. To improve mobility of stroke patients & 41 & 75.92 & 5 & 9.25 & 8 & 14.81 & 89 \\
\hline 8. To prevent and recover from sport injuries & 51 & 94.44 & 0 & 0 & 3 & 5.55 & 98 \\
\hline 9. To prevent fall of high risk people & 40 & 74.07 & 3 & 5.55 & 11 & 20.37 & 90 \\
\hline 10. To reduce or recover from vertigo condition. & 10 & 18.51 & 26 & 48.14 & 18 & 33.33 & 57 \\
\hline 11. To help in rehabilitation of burn condition & 18 & 33.33 & 20 & 37.03 & 16 & 29.62 & 65 \\
\hline 12. To help the recovery of patient of cerebral palsy & 9 & 16.66 & 20 & 37.03 & 25 & 46.29 & 60 \\
\hline 13. To help in case of head injuries & 32 & 59.25 & 8 & 14.8 & 14 & 25.92 & 81 \\
\hline 14. To help cases of quadriplegia contrition & 21 & 38.88 & 22 & 40.74 & 14 & 25.92 & 66 \\
\hline 15. To help the rehabilitation of fracture cases & 34 & 62.96 & 9 & 1.66 & 11 & 20.37 & 82 \\
\hline
\end{tabular}

Overall mean percent score $=79.66 \%$

The distribution of students' responses regarding women's health was highly correct $81.48 \%$ with percent sore $91 \%$ regarding recovery from osteoarthritis and osteoporosis, the lowest proportion of correct responses
$9.25 \%$ with percent score $49 \%$ regarding the caring of women before and after pregnancy The overall percent score for this domain $=67 \%$ as shown in table (3).

Table 3: Distribution of knowledge of students regarding women's health $(\mathrm{N}=54)$

\begin{tabular}{|l|c|c|c|c|c|c|c|}
\hline \multirow{2}{*}{ Women's Health } & \multicolumn{2}{|c|}{ Yes } & \multicolumn{2}{|c|}{ No } & \multicolumn{2}{c|}{ Don't Know } & \multirow{2}{*}{$\begin{array}{c}\text { Percent } \\
\text { score }\end{array}$} \\
\cline { 2 - 8 } & No & $\%$ & No & $\%$ & No & \% & 49 \\
\hline 1. To help in caring of women before and after pregnancy & 5 & 9.25 & 34 & 62.96 & 15 & 27.77 & 49 \\
\hline 2. To help women with breast cancer & 13 & 24.07 & 19 & 35.18 & 22 & 40.74 & 63 \\
\hline 3. To decrease pelvic pain & 14 & 25.92 & 17 & 31.48 & 23 & 42.59 & 65 \\
\hline $\begin{array}{l}\text { 4. To help in recovery from osteoarthritis and } \\
\text { osteoporosis. }\end{array}$ & 44 & 81.48 & 4 & 7.40 & 6 & 11.11 & 91 \\
\hline
\end{tabular}

Overall mean percent score $=67 \%$

The distribution of student's responses regarding the benefits of physiotherapy in the management of chronic diseases was with highest correct proportions $85.18 \%$ with percent score $92 \%$ regarding helping in case of urinary incontinence while the lowest correct proportions $42.49 \%$ with percent $76 \%$ regarding care of patients with burns and peptic ulcers. The overall percent score for this domain is $84 \%$ as shown in table (4). 
Table (4): Distribution of knowledge of students regarding the benefits of physiotherapy in chronic diseases $(\mathbf{N}=\mathbf{5 4})$

\begin{tabular}{|c|c|c|c|c|c|c|c|}
\hline \multirow{2}{*}{ Chronic disease } & \multicolumn{2}{|c|}{ Yes } & \multicolumn{2}{|c|}{ No } & \multicolumn{2}{|c|}{ Don't Know } & \multirow{2}{*}{$\begin{array}{l}\text { Percent } \\
\text { score }\end{array}$} \\
\hline & No & $\%$ & No & $\%$ & No & $\%$ & \\
\hline 1. To help in rehabilitation of cardiac problems. & 23 & 42.59 & 6 & 11.11 & 16 & 29.62 & 66 \\
\hline 2. To help in rehabilitation of pulmonary problems & 44 & 81.48 & 6 & 11.11 & 4 & 7.40 & 90 \\
\hline $\begin{array}{l}\text { 3. To improve sensation of feet and legs of patients of } \\
\text { diabetes mellitus }\end{array}$ & 37 & 68.51 & 6 & 11.11 & 11 & 20.37 & 86 \\
\hline 4. To care for patients with burns and peptic ulcers. & 23 & 42.49 & 8 & 14.81 & 23 & 42.49 & 76 \\
\hline 5. To help in case of urinary in continuance & 46 & 85.18 & 5 & 9.25 & 3 & 5.5 & 92 \\
\hline 6. To help cases of fecal continuance. & 45 & 83 & 5 & 9.25 & 4 & 7.40 & 93 \\
\hline
\end{tabular}

Overall mean percent score $=84 \%$

\section{Discussion}

Physiotherapy (PT) has been considered as a method of treatment throughout the long term and is quickly developing as a calling, particularly in creating nations. ${ }^{(9,10)}$

The present study evaluated the knowledge of junior college and institute students regarding the benefits of physiotherapy. The results indicated that the students had a varied knowledge regarding the benefits physiotherapy services.

Regarding the orthopedic prevention and recovery from sport injuries, the students correct responses was $94.44 \%$ with percent score $98 \%$, in comparison in Harare,Zimbabwe the participants indicated that physiotherapists should assist the first aid treatment of sport related injuries $92.2 \%{ }^{(11)}$.

Physical therapists can fit people with any of assistive devices or orthotic prescription adapted to ensure maximal performance and safety ${ }^{(12)}$ and the students correct responses was $79 \%$ with percent score $90 \%$.

Remedial activities and manual treatment method, for example, joint and delicate tissue assembly medicines, activation and delicate tissue back rub can assist with easing torment and improve quality ${ }^{(12)}$.

The students' responses were $77.77 \%$ with percent score $86 \%$ while the results of Harare, Zimbabwe study revealed that the majority knew that physiotherapy optimizing movement efficiency $95.1 \%$.for muscle pain, $88.2 \%$ for ligament injuries, use of exercise machines but only $31.4 \%$ knew that physiotherapy use electrotherapy equipment, in addition $90.2 \%$ knew about massage $\left({ }^{11)}\right.$.

Physical advisors can perform explicit moves that can rapidly reestablish appropriate vestibular working, and diminish and dispense with manifestations of unsteadiness or vertigo and improve balance conditions ${ }^{(12)}$. however understudies reactions was baffling $18.51 \%$ with percent score, $57 \%$.

As a feature of maturing measure, individuals may create joint pain or osteoporosis or need a joint substitution some of the time. Physical advisors can assist patients with recouping from joint substitution, and oversee ligament or osteoporotic conditions moderately (12). and understudy's reactions was $81.48 \%$, with percent score $91 \%$. In Ischikkawa, high school students showed accurate responses regarding instruct a client in exercises $68.4 \%$, doing massage $58.5 \%$, works with joint decrease pain/stiffness $34.7 \%\left({ }^{13)}\right.$.

In kwazula Natal,the students responses about conditions treated by physiotherapists $79 \%$ for arthritis and the majority of respondents knew that physiotherapists could manage musculo-skeletal conditions. ${ }^{(14)}$

As to's Health,as ladies have explicit medical issue, for example, with pregnancy and baby blues care. Physical advisors can offer particular administration of issues identified with ladies' wellbeing ${ }^{(12)}$ and students' responses was $9.2 \%$ with percent score $49 \%$. In kwazula Natal students' responses was disappointing 19.4\% for ante-natal care ${ }^{(14)}$. 
Prati V and Liu $\mathrm{H}$ in their study found that the respondents were generally not aware that physiotherapy could manage antenatal care. ${ }^{(15)}$

Role of physiotherapy in the management of chronic diseases and their complications like urinary incontinence by offering specialized treatment and students correct responses was $85,18 \%$. while the help in rehabilitation of cardiac conditions $42.59 \%$ while in Harare, Zimbabwe ${ }^{(11)}$, the majority of students showed awareness in that physiotherapists do not manage cardiac pain $86.3 \%$

The majority of respondents of Kwazulo Natal. not identified that physiotherapists work with patients with respiratory disease or thoracic surgery and fewer identified obstetrics and gynecology. ${ }^{(14) .}$

Cerebral paralysis (CP) is a gathering of perpetual development problems that show up in early childhood $^{(16)}$. Signs and manifestations differ among individuals and after some time. ${ }^{(16,17)}$

There is no solution for CP; be that as it may, steady medicines, prescriptions and medical procedure may support numerous people. Physiotherapy is critical to diminish spasticity and disfigurement ${ }^{(18)}$, furthermore, the understudies' reactions were just right in $33.3 \%$.

\section{Conclusions}

The knowledge level of students regarding benefits of physiotherapy in general was satisfactory.

\section{Recommendations:}

1. The examination featured the need to lead a comparative report with bigger example size to evaluate information with different establishments and schools.

2. There is consistent requirement for a focused on training and mindfulness program for understudies having a place with various schools present in various Iraqi governorates.

Acknowledgment: Should be offered to all participatedPhysiotherapy students of Medical Technical Institute, Technical College of Health and Medicine/ Baghdad.

The source of funding for the study was selfdependence
Conflict of Interests: Was just limited time in data collection.

\section{References}

1. Jump up "Physical Therapists". careerswiki. Retrieved 13 November 2014.

2. American Physical Therapy Association, Role of physical therapists Guide to physical Therapists practices, $2^{\text {nd }}$ Edition 2003.

3. Pallavi Vitthal Bargaje, Nilima S Bedekar, Savita Rairikar, etal,perception of junior college students about Physiotherapy as a profession. Journal of Indian Asscciation, 2017, vol 11. Issue 1 :30-33 .

4. American Physical Therapy Association (17 January 2008). "APTA Background Sheet 2008”. American Physical Therapy Association. Archived from the original on 29 May 2008. Retrieved 29 May 2008.

5. Kerss JJ, Groenew egenPP: Referrals in physiotherapy: the relation between the number of referrals, the indication for referral and inclination to refer.Soc Sci Med,1990,30:797-804

6. Tuner P. The occupational prestige of phsiotherapy, perceptions of student physiotherapists in Ausrralia, Australian J of Phsiotherapy, 2001,47,191-200.

7. Hawk C, Buckwalter K, Byrid L,Cigeman et al. professions students perceptions pf interprofessional relationships Academic Medicine, 2002, 77:345-357

8. Harry N. Boone JR, Deborah A. Boone. Analyzing Likert data. Journal of extension, 2012,vol.50,no-2, Article number 2TOT2.

9. Murphy BP, Greathouse D, Matsui I: Primary care physical therapy practice models. J Orthop Sports Phys Ther, 2005, 35: 699-707.

10. James JJ, Stuart RB: Expanded role for the physical therapist. Screening musculoskeletal disorders. Phys Ther, 1975, 55: 121-131.

11. Chiwaridzo M,Msiska MLLevel of physiotherapy among high school sports coaches in Harare,Zimbabwe,International $\mathrm{J}$ of Scientific and Research publications,2015,vol5,Tssue 10:1-11.

12. Rehab insights Prioneering Rehabilitation10 reasons why physical therapy is beneficial,2012.

13. Ogiwara SRP R,ONC et al,Knowledge of physiotherapy:A study of Ishikawa high school students of Phys Ther: Sci, 2005,17:9-16; 
14. Pucknee T, Harinarush RB, Ramdath PB et 1 . knowledge, perceptions and attitudes of final year medical, occupational theapy and sportscience students regarding physiotheapy in Kwazula Natal, SA journal of Phsiotherapy, 2011, vol 67: no. 3: 19-26.

15. Prati V and Liu .Perceptions of college students regarding the current physical therapy profession and professional education process. The Internet journal of Allied sciences and practices, 2006,4:1-6.

16. Jump up to: "Cerebral Palsy: Hope Through Research". National Institute of Neurological Disorders and Stroke. July 2013. Archived from the original on 21 February 2017. Retrieved 21 February 2017.

17. Haak, Peterson; Lenski, Madeleine; Hidecker, Mary Jo Cooley; Li, Min; Paneth, Nigel (October 2009). "Cerebral palsy and aging". Developmental Medicine \& Child Neurology. 51: 16-23. doi:10.1111/j.1469-8749.2009.03428.x. PMC 4183123. PMID 19740206.

18. "How many people are affected?". National Institutes of Health. 5 September 2014. Archived from the original on 2 April 2015. Retrieved 4 March 2015. 